\title{
O leucograma como indicador de estresse no desmame e no transporte rodoviário de bovinos da raça Nelore
}

\section{The leukogram as an indicator stress on weaning and after road transport in Nelore calfs}

\author{
Paulo Ricardo de Oliveira Paes ${ }^{1 *}$; Roberto Calderon Gonçalves ${ }^{2}$; Graziela Barioni ${ }^{3}$; \\ Fabiola de Oliveira Paes Leme ${ }^{1}$; Marília Martins Melo ${ }^{1}$; Mariângela Lozano Cruz ${ }^{4}$
}

\begin{abstract}
Resumo
O estresse pode causar perdas econômicas devido ao menor ganho de peso e a maior susceptibilidade dos animais às doenças. Entre os eventos causadores de estresse em bezerros, destacam-se o desmame e o transporte rodoviário, que podem determinar o aumento das concentrações séricas de adrenalina e/ ou cortisol. Este trabalho objetivou avaliar a influência do desmame e do transporte rodoviário sobre o leucograma de bezerros da raça Nelore. Para tal foram utilizados 30 bovinos com sete a oito meses de idade, divididos em três grupos, sendo o primeiro composto por animais em lactação (GL), o segundo por animais em desmame (GD) e o terceiro por animais em desmame submetidos ao transporte rodoviário por quatro horas (GDT). No primeiro dia de desmame, mas não no dia subseqüente, observaram-se no GD e GDT alterações leucocitárias compatíveis com a ação da adrenalina, como elevações significativas $(\mathrm{p}<0,05)$ das contagens de leucócitos e neutrófilos, sem alteração da relação neutrófilos:linfócitos (NL). No GDT, imediatamente após o transporte rodoviário, mas não no dia subseqüente, observaramse alterações leucocitárias $(\mathrm{p}<0,05)$ compatíveis com a ação do cortisol, como elevação da relação N:L e diminuição da contagem de eosinófilos. Concluiu-se que, nas condições do presente experimento, há alterações leucocitárias no desmame e no transporte rodoviário de bezerros relacionadas com a ação da adrenalina e cortisol, respectivamente, e que o leucograma pode ser utilizado como indicador de estresse no manejo desta espécie.
\end{abstract}

Palavras-chave: Bezerros, hemograma, estresse, adrenalina, cortisol

\begin{abstract}
Stress can cause economic losses due to lower weight gain and increased susceptibility of animal diseases. Among the events that cause stress in calves, stand out weaning and road transport, which can result in increased serum concentrations of adrenaline and / or cortisol. This study evaluated the influence of weaning and road transport on the leukogram of Nelore calves. With this purpose, 30 calves with seven to eight months of age, divided into three groups, the first being composed of lactating animals (GL), the second by weaning animals (GD) and the third by weaning animals subjected to road transport for four hours (GDT). The first day of weaning, but not in subsequent days, there were changes in GD and GDT leukogram compatible with the action of adrenaline, as significant increases counts of WBC and neutrophils $(\mathrm{p}<0.05)$, without changing in the neutrophil lymphocytes ratio (NL).
\end{abstract}

\footnotetext{
1 Profs. do Dept ${ }^{\circ}$ de Clínica e Cirurgia Veterinárias da Escola de Veterinária da Universidade Federal de Minas Gerais, UFMG. Belo Horizonte, MG. E-mail: paulopaes@vet.ufmg.br; fabiola.ufmg@gmail.com; mariliamm@ufmg.br

2 Prof. do Dept $^{\circ}$ de Clínica da Faculdade de Medicina Veterinária e Zootecnia da UNESP, Campus de Botucatu, SP. E-mail: calderon@fmvz.unesp.br

3 Prof ${ }^{a}$ do Centro de Ciências Agrárias, Universidade Federal do Espírito Santo, UFES. E-mail: graziela.barioni@terra.com.br

4 Médica Veterinária autônoma. E-mail: neca.cruz@yahoo.com.br

* Autor para correspondência
} 
In the GDT, immediately after transport, but not in subsequent days, leukogram changes were ( $\mathrm{p}<$ 0.05 ) compatible with the action of cortisol, as higher $\mathrm{N}$ : L ratio and decreased eosinophil count. It was concluded that, under the conditions of this experiment, there are changes in leukocytes on weaning and road transport related to the action of adrenaline and road transport, respectively, and that the WBC can be used as an indicator of stress in this species.

Key words: Calves, hemogram, stress, adrenaline, cortisol

\section{Introdução}

As reações do estresse representam modificações dos mecanismos fisiológicos que tem como objetivo a manutenção da homeostase do animal. Apesar das reações do estresse serem organizadas para a proteção da homeostasia, elas contêm elementos que podem aumentar a susceptibilidade às doenças (BREAZILE, 1998). O córtex e a medula adrenal são os principais participantes na adaptação ao estresse, liberando cortisol e adrenalina, respectivamente, que aumentam a produção e o desvio de glicose para o sistema nervoso central (GENUTH, 2000). A adrenalina também induz a mobilização de leucócitos do compartimento vascular marginal para o compartimento circulante, particularmente os neutrófilos e linfócitos, o que resulta na alteração denominada leucocitose fisiológica (SMITH, 2000). Como a adrenalina, os corticosteróides induzem a neutrofilia, embora a ação ocorra por mecanismos diferentes: liberação de neutrófilos da medula óssea, menor migração destes para os tecidos e diminuição da aderência à parede vascular (STOCKHAM; SCOTT, 2002). Os corticosteróides ainda, ao contrário da adrenalina, induzem a linfopenia por meio da linfólise e da diminuição da recirculação dos linfócitos (JAIN, 1993).

O estresse dos animais pode ocorrer por motivos físicos, como fome, fadiga, lesão e temperatura extrema, ou por fatores psicológicos, como medo (GRANDIN, 1997). Segundo Loerch e Fluharty (1999), o desmame é possivelmente um dos fatores mais estressantes no manejo de bezerros de criação de corte, uma vez que a separação das mães é realizada de maneira abruptal. Smith et al. (2003) observaram mais sinais de estresse e desempenho de crescimento inferior em animais desmamados precocemente aos quatro meses de idade o que, segundo Catto e Afonso (2001) e Baker-Neff et al. (2001), resultam em perdas econômicas relacionadas ao ganho de peso dos animais. Lefcourt e Elsasser (1995) relataram aumento da concentração sérica de adrenalina e manutenção da concentração de cortisol no desmame, enquanto Hickey, Drennan e Earley (2003) não observaram alterações nas concentrações destes hormônios durante o desmame. Coppo, Rasby e Clemens (2003) relataram maiores contagens de leucócitos, neutrófilos e linfócitos, ao passo que Fell et al. (1999), Bueno, Rasby e Clemens (2003) e Smith et al. (2003) não observaram alterações no leucograma de animais em desmame.

Segundo Loerch e Fluharty (1999), o transporte rodoviário é provavelmente o evento mais exaustivo na vida de um bezerro. Wernicki et al. (2006) relataram aumento das concentração sérica de cortisol em bezerros, que permaneceu elevada após nove dias de transporte rodoviário por duas horas. Steinhardt (2002), entretanto, constatou apenas um discreto aumento do cortisol sérico após o transporte rodoviário, com retorno ao valor controle do hormônio no dia seguinte ao evento. Villaroel et al. (2003) constataram que a concentração de cortisol sérico e a relação neutrófilos:linfócitos é maior nos bovinos transportados em trajetos de uma a duas horas em comparação à períodos menores ou maiores. Phillips et al. (1989) e Tadich et al. (2003) observaram leucocitose em bovinos submetidos ao transporte rodoviário.

O presente trabalho teve como objetivo estudar a influência dos primeiros dias do desmame e do transporte rodoviário sobre o leucograma de bovinos da raça Nelore criados em condição extensiva de produção. 


\section{Material e Métodos}

Foram utilizados 30 bovinos da raça Nelore, criados em regime de pasto de Brachiaria decumbens na Fazenda Cananéia, Município de Linhares, Estado do Espírito Santo. Os animais foram distribuídos em três grupos, compostos por cinco machos e cinco fêmeas com idade de sete a oito meses. No grupo controle, denominado grupo lactente (GL), os animais permaneceram com as mães durante todo o experimento, sendo momentaneamente afastados para a coleta de amostras. Nos grupos desmame (GD) e desmame e transporte (GDT), os animais foram afastados das mães e confinados no curral durante a primeira noite de desmame, sendo mantidos sob privação de água e alimentos. No dia seguinte o GDT foi submetido ao transporte rodoviário em um caminhão com tara 7.500 e lotação de $15.000 \mathrm{~kg}$, locados em um compartimento de aproximadamente $11 \mathrm{~m}^{2}$, resultando em uma densidade de aproximadamente $200 \mathrm{~kg} / \mathrm{m}^{2}$. Os animais trafegaram por estrada não pavimentada em condições precárias devido às chuvas, por um período de quatro horas, para concluir um trajeto de cinqüenta quilômetros sob temperatura média de $23,5^{\circ} \mathrm{C}$ e umidade relativa do ar de $80 \%$. Após a coleta de dados, os animais do GD e do GDT foram liberados para diferentes piquetes, onde permaneceram sem contato visual com as mães.

Os animais foram encaminhados ao tronco de contenção, quando foram submetidos à coleta de sangue em quatro momentos, denominados de acordo com o manejo do GD e/ou GDT, conforme descrito a seguir: 1) Momento controle: MD0T-12, momento do desmame (GD e GDT) e a 12 horas do embarque para o transporte (GDT); 2) MD12T0, momento de 12 horas do início do desmame (GD e GDT) e imediatamente anterior ao início do transporte (GDT); 3) MD16T4, momento de 16 horas do início do desmame (GD) e imediatamente após o término do transporte (GDT); 4) MD36T20, momento de 36 horas do início do desmame (GD) e de 20 horas do término do transporte (GDT).

Para a obtenção das amostras de sangue foram utilizados tubos à vácuo, sendo obtidos mediante punção da jugular, $5 \mathrm{~mL}$ de sangue em tubo com anticoagulante ácido etilenodiaminotetracético (EDTA) para a realização do leucograma. Imediatamenteapósacoleta, os esfregaçossanguíneos foram confeccionados em lâmina de vidro, corados com corante rápido do tipo Romanowsky, secados ao ar e armazenados em recipiente apropriado. Os tubos com amostras de sangue foram mantidos sob refrigeração até o momento das contagens de leucócitos totais, realizadas em hemocitômetro no mesmo dia da coleta, conforme técnica descrita por Jain (1993). O exame diferencial dos leucócitos foi realizado avaliando-se 100 leucócitos em aumento microscópico de $1.000 x$, levando-se em consideração alterações morfológicas como neutrófilos tóxicos, linfócitos reativos e monócitos ativados, conforme técnica descrita Harvey (2000).

Para a comparação dos resultados de cada variável entre os momentos, dentro de cada grupo, foi utilizado o teste não paramétrico de Friedman. Para a comparação dos resultados de cada variável entre os grupos, dentro de cada momento, foi utilizado o teste não paramétrico de KruskalWallis. Em todas as análises, as estatísticas foram consideradas significativas quando $\mathrm{p}<0,05$ (ZAR, 1994).

\section{Resultados e Discussão}

Os resultados das contagens de leucócitos, neutrófilos, linfócitos, monócitos e eosinófilos, e da relação neutrófilos:linfócitos $(\mathrm{N}: \mathrm{L})$ dos animais dos três grupos, nos momentos avaliados, estão representados pelas medianas na tabela 1 .

As medianas das contagens de leucócitos totais dos três grupos ficaram acima dos limites de referência propostos por Jain (1993) em todos os momentos avaliados. Quando comparados aos valores da literatura nacional para a raça Nelore, os valores de leucócitos totais obtidos foram superiores aos relatados por Fagliari et al. (1998) e Paes et al. (2003) e próximos aos obtidos por Costa et al. (1994) e Benesi et al. (2002). 
Tabela 1. Medianas e análise estatística de quatro repetições das contagens de leucócitos totais (céls/ $\mu \mathrm{L})$, neutrófilos (céls $/ \mu \mathrm{L}$ ), linfócitos (céls $/ \mu \mathrm{L}$ ), eosinófilos (céls/ $\mu \mathrm{L}$ ) e monócitos (céls/ $\mu \mathrm{L}$ ) e da relação neutrófilos/linfócitos $(\mathrm{N}: \mathrm{L})$ de bovinos da raça Nelore de sete a oito meses de idade, dos grupos lactentes (GL), desmamados (GD) e desmamados e submetidos ao transporte rodoviário por quatro horas (GDT), segundo os momentos avaliados.

\begin{tabular}{|c|c|c|c|c|c|c|}
\hline \multirow{2}{*}{ Variável } & \multirow{2}{*}{ Grupos } & \multicolumn{4}{|c|}{ Momentos } & \multirow{2}{*}{$\begin{array}{l}\text { Valores de } \\
\text { Referência }\end{array}$} \\
\hline & & MD0T-12 & MD12T0 & MD16T4 & MD36T24 & \\
\hline \multirow{3}{*}{$\begin{array}{l}\text { Leucócitos Totais } \\
\text { (céls } / \mu \mathrm{L} \text { ) }\end{array}$} & GL & $15.075 \mathrm{a}$ & $14.425 \mathrm{a}$ & $17.750 \mathrm{a}$ & $15.500 \mathrm{a}$ & \multirow{3}{*}{$4.000-12.000$} \\
\hline & GD & $16.000 \mathrm{a}$ & $15.275 \mathrm{a}$ & $18.600 \mathrm{~b}$ & $15.175 \mathrm{a}$ & \\
\hline & GDT & $12.950 \mathrm{a}$ & $16.975 \mathrm{~b}$ & $15.175 \mathrm{a}$ & $15.400 \mathrm{a}$ & \\
\hline \multirow{3}{*}{$\begin{array}{l}\text { Neutrófilos } \\
\text { (céls/ } \mu \mathrm{L} \text { ) }\end{array}$} & GL & $3.707 \mathrm{a}$ & $4.325 \mathrm{a}$ & $4.930 \mathrm{a}$ & $2.429 \mathrm{a}$ & \multirow{3}{*}{$600-4.000$} \\
\hline & GD & $2.832 \mathrm{a}$ & $4.217 \mathrm{~b}$ & $5.230 \mathrm{~b}$ & $2.312 \mathrm{a}$ & \\
\hline & GDT & $2.429 \mathrm{a}$ & $4.152 \mathrm{a}$ & $4.884 \mathrm{~b}$ & $3.234 \mathrm{a}$ & \\
\hline \multirow{3}{*}{$\begin{array}{l}\text { Linfócitos } \\
\text { (céls } / \mu \mathrm{L})\end{array}$} & GL & $9.165 \mathrm{Aa}$ & $9.084 \mathrm{Aa}$ & $11.213 \mathrm{Ba}$ & $10.552 \mathrm{Aa}$ & \multirow{3}{*}{$2.500-7.500$} \\
\hline & GD & $10.486 \mathrm{Abc}$ & $8.096 \mathrm{Ab}$ & $11.255 \mathrm{Bc}$ & $9.820 \mathrm{Abc}$ & \\
\hline & GDT & $8.602 \mathrm{Aa}$ & $12.087 \mathrm{Aa}$ & $8.889 \mathrm{Aa}$ & $9.565 \mathrm{Aa}$ & \\
\hline \multirow{3}{*}{$\begin{array}{l}\text { Neutrófilos/ } \\
\text { Linfócitos } \\
(\mathrm{N} / \mathrm{L})\end{array}$} & GL & $0,28 \mathrm{a}$ & $0,48 \mathrm{a}$ & $0,41 \mathrm{~b}$ & $0,28 \mathrm{a}$ & \multirow{3}{*}{$0,24-0,53$} \\
\hline & GD & $0,23 \mathrm{a}$ & $0,53 \mathrm{a}$ & $0,47 \mathrm{a}$ & $0,22 \mathrm{a}$ & \\
\hline & GDT & $0,31 \mathrm{~b}$ & $0,37 \mathrm{~b}$ & $0,61 \mathrm{a}$ & $0,28 \mathrm{a}$ & \\
\hline \multirow{3}{*}{$\begin{array}{l}\text { Eosinófilos } \\
\text { (céls/ } \mu \mathrm{L} \text { ) }\end{array}$} & GL & $394 \mathrm{Aab}$ & $331 \mathrm{Ab}$ & $78 \mathrm{Aa}$ & $290 \mathrm{Aa}$ & \multirow{3}{*}{$0-2.400$} \\
\hline & GD & $599 \mathrm{Aa}$ & $850 \mathrm{Ab}$ & $479 \mathrm{Ba}$ & $833 \mathrm{Ba}$ & \\
\hline & GDT & $587 \mathrm{Ab}$ & $465 \mathrm{Ab}$ & $0 \mathrm{Aa}$ & $871 \mathrm{Ab}$ & \\
\hline \multirow{3}{*}{$\begin{array}{l}\text { Monócitos } \\
(\text { céls } / \mu \mathrm{L})\end{array}$} & GL & 1.275 & 1.299 & 1.378 & 1.080 & \multirow{3}{*}{$25-840$} \\
\hline & GD & 792 & 1.451 & 1.050 & 922 & \\
\hline & GDT & 1.165 & 996 & 1.340 & 1.065 & \\
\hline
\end{tabular}

Letras minúsculas. Para cada grupo, momentos representados pelas medianas seguidas de letras iguais não diferem significativamente $(\mathrm{p}>0,05)$.

Letras maiúsculas. Para cada momento, grupos representados pelas medianas seguidas de letras iguais não diferem significativamente $(\mathrm{p}>0,05)$.

No momento controle (MD0T-12) as contagens de leucócitos totais elevadas ocorreram devido às altas contagens de linfócitos, já que as contagens de neutrófilos, assim como as demais variáveis do leucograma, estavam dentro dos limites de referência. Como não havia influência do desmame ou transporte, já que a coleta de amostra se deu imediatamente após a apartação dos bezerros do contato com as mães, esta "linfocitose" pode ser atribuída ao maior contato dos animais criados em condições subtropicais com antígenos, como ectoparasitos e endoparasitos, já que os valores de referência utilizados foram estabelecidos em animais adultos de países de clima temperado do hemisfério norte. A hipótese da linfocitose ter ocorrido por influência da liberação de adrenalina, reação típica do estresse agudo da contenção, foi descartada pela ausência de neutrofilia concomitante. Estes achados determinaram a ocorrência de baixa relação neutrófilos:linfócitos (N:L) quando os valores medianos do momento controle (MD0T-12) foram comparados aos obtidos por Jain (1993) e Fagliari et al. (1998).

Na primeira avaliação pós-demame (MD12T0), enquanto o grupo controle (GL) não apresentou variações significativas nas contagens de leucócitos totais, neutrófilos, linfócitos e eosinófilos, o GD apresentou elevações significativas das contagens de neutrófilos e eosinófilos $(p<0,05)$ e o GDT apresentou elevação significativa da contagem de leucócitos totais $(p<0,05)$. Estas alterações nos grupos de animais desmamados (GD e GDT), com elevações das contagens de leucócitos totais ou neutrófilos, sem alteração na relação N:L, são compatíveis com a 
liberação de leucócitos do compartimento marginal para o compartimento circulante por influência da adrenalina. Como estas alterações não foram observadas no GL, sugerem estar correlacionadas com o estresse das primeiras 12 horas de desmame. Também investigando o desmame de bezerros, Coppo, Rasby e Clemens (2003) relataram alterações leucocitárias semelhantes e Lefcourt e Elsasser (1995) relataram aumento da concentração sérica de adrenalina. Entretanto, Fell et al. (1999), Bueno, Rasby e Clemens (2003) e Smith et al. (2003) não observaram alterações no leucograma de animais em desmame, enquanto Hickey, Drennan e Earley (2003) não observaram alterações nas concentrações hormonais durante este período. Segundo Grandin (1997), as variáveis envolvidas no estresse justificam os resultados aparentemente conflitantes das pesquisas sobre o tema.

No momento seguinte (MD16T4), enquanto o grupo controle (GL) novamente não apresentou variação nas contagens celulares, o GD apresentou manutenção da alta contagem de neutrófilos, desta vez acompanhada de aumento da contagem de linfócitos $(p<0,05)$, o que determinou em elevação da contagem de leucócitos totais $(p<0,05)$. Estes resultados são compatíveis com a manutenção da ação da adrenalina sobre os leucócitos dos animais desmamados.

No mesmo momento (MD16T4), o grupo submetido ao transporte rodoviário (GDT) apresentou diferentes alterações nas contagens celulares em relação ao GL e ao GD. No GDT o aumento significativo da contagem de neutrófilos $(p<0,05)$ determinou em diminuição da relação $\mathrm{N}: \mathrm{L}$ $(p<0,05)$, enquanto a diminuição significativa da contagem de eosinófilos $(p<0,05)$, resultaram em diferença significativa da variável na comparação entre GDT e GD $(p<0,05)$. Estas alterações são compatíveis com influência do cortisol, que determina, conforme Jain (1993) e Stockham e Scott (2002), em neutrofilia, por liberação de neutrófilos da medula óssea, menor migração destes para os tecidos e diminuição da aderência à parede vascular; linfopenia, por meio da linfólise e da diminuição da recirculação dos linfócitos; e eosinopenia, por mecanismo ainda não esclarecido. Além disso, a adrenalina pode causar eosinofilia, o que justifica a ocorrência de diferença nesta variável entre o GDT e o GD. Estes resultados estão em concordância como os obtidos por Steinhardt (2002), Villaroel et al. (2003) e Wernicki et al. (2006), que relataram aumento das concentração sérica de cortisol em bezerros após o transporte rodoviário, e com os relatos de Phillips et al. (1989) e Tadich et al. (2003), que descreveram o ocorrência de leucocitose em bovinos submetidos ao mesmo evento.

No MD36T24 as contagens de leucócitos totais, neutrófilos, linfócitos e eosinófilos, assim como a relação $\mathrm{N}: \mathrm{L}$, retornaram a valores semelhantes aos do momento controle (MD12T0) no GD e GDT. No GD este resultado demonstra que, entre outras variáveis, o tempo decorrido no momento da avaliação pode influenciar nos resultados de pesquisas sobre alterações leucocitárias influenciadas pelo desmame em bovinos, já que as alterações observadas 12 e 16 horas após o início do desmame, não foram observadas no dia seguinte. No GDT as alterações leucocitárias observadas imediatamente após o transporte rodoviário e atribuídas à influência do cortisol, também não foram constatadas no dia seguinte. Este resultado é compatível com o relato de Steinhardt (2002), que observaram retorno da concentração sérica de cortisol aos níveis do momento controle após 24 horas do transporte rodoviário, mas difere dos resultados de Wernicki et al. (2006) que relataram manutenção da concentração elevada deste hormônio durante nove dias. Como Villaroel et al. (2003) relataram que as maiores elevações das concentrações de cortisol são observadas após as viagens de duas horas, como a do presente experimento, quando comparados as viagens menores ou maiores, o retorno das contagens leucocitárias aos valores controle não podem ser atribuídas ao tempo de viagem.

Os resultados obtidos no presente experimento, com alterações leucocitárias atribuídas a influências 
hormonais, indicam que o leucograma pode ser empregado em avaliações de manejo de desmame e de transporte bovino, com a vantagem, em comparação as mensurações hormonais, do baixo custo e da menor exigência tecnológica utilizada.

\section{Conclusões}

Conclui-se que no desmame de bovinos da raça Nelore aos sete a oito meses de idade ocorrem alterações no leucograma compatíveis com ação da adrenalina no primeiro dia de desmame e retorno aos valores iniciais no dia seguinte e que, imediatamente após o transporte rodoviário por quatro horas, mas não no dia subsequente, estes animais têm alterações no leucograma compatíveis com ação do cortisol, o que caracteriza o leucograma como um bom indicador de estresse no manejo de desmame e transporte de bezerros.

\section{Referências}

BAKER-NEEF, J. M.; BUSKIRK, D. D.; BLACK, J. R.; DOUMIT, M. E.; RUST, S. R. Biological and economic performance of early-weaned Angus steers. J. Anim. Sci., Madison, v. 79, n. 11, p. 2762-2769, 2001.

BENESI, F. J.; COSTA, J. N.; BIRGEL, E. H.; D'ANGElinO, J. L.; AYRES, M. C. C.; BARROSFILHO, I. R. Leucograma padrão de bovinos da raça Nelore (Bos indicus). Influência de fatores sexuais. Vet. Notícias, Uberlândia, v. 8, n. 1, p. 59-66, 2002.

BREAZILE, J. E. The physiology of stress and its relationship to mechanisms of disease and therapeutics. Vet. Clin. North Am: Food Anim. Pract., Philadelphia, v. 4, n. 3, p. 441-478, 1988.

BUENO, A. R.; RASBY, R.; CLEMENS, E. T. Age at weaning and the endocrine reponse to stress. Arq. Bras. Med. Vet. Zootec., Belo Horizonte, v. 55, n. 1, p. 1-7, 2003.

CATTO, J. B.; AFONSO, E. Taxa de natalidade de vacas e desempenho de bezerros sob desmama antecipada no Pantanal. Pesq. Agrop. Bras., Brasília, v. 36, n. 9, p. 1205-1211, 2001.

COPPO, J. A.; MUSSART, N. B.; REVIDATTI, M. A.; CAPELLARI, A. Absence of biochemically demonstrable stress in early weaned half-bred zebu calves. Cien. Inv. Agr., Santiago, v. 30, n. 2, p. 97-105, 2003.

COSTA, J. N. Leucograma de zebuínos (Bos indicus) raça Nelore, criados no estado de São Paulo: influência de fatores etários, sexuais e do tipo racial. 1994. Dissertação (Mestrado em Clínica) - Faculdade de Medicina Veterinária e Zootecnia. Universidade de São Paulo, São Paulo.

FAGLIARI, J. J.; SANTANA, A. E.; LUCAS, F. A.; CAMPOS FILHO, E.; CURI, P. R. Constituintes sangüíneos de bovinos lactantes, desmamados e adultos das raças Nelore (Bos indicus) e Holandesa (Bos taurus) e de bubalinos (Bubalus bubalis) da raça Murrah. Arq. Bras. Med. Vet. Zootec., Belo Horizonte, v. 50, n. 3, p. 263-271, 1998.

FELL, L. R.; COLDITZ, I. G.; WALKER, K. H.; WATSON, D. L. Associations between temperament, performance and immune function in cattle entering a commercial feedlot. Austr. J. Exper. Agric., Melbourne, v. 39, n. 7, p. 795-802, 1999.

GENUTH, S. M. O sistema endócrino. In: BERNE, R. M.; MATTHEW, N. L. Fisiologia. Rio de Janeiro: Guanabara Koogan, 2000. p. 476-497.

GRANDIN, T. Assessment of stress during handling and tranport. J. Anim. Sci., Madison, v. 75, n. 1, p. 249-257, 1997.

HARVEY, J. W. Atlas of veterinary hematology: blood and bone marrow of domestic animals. Philadelphia: Saunders, 2001. 228 p.

HICKEY, M. C.; DRENNAN, M.; EARLEY, B. The effect of abrupt weaning of suckler calves on the plasma concentrations of cortisol, catecholamines, acute-phase proteins and in vitro interferon-gamma production. $J$. Anim. Sci., Madison, v. 81, n. 11, p. 2847-2855, 2003.

JAIN, N. C. Essentials of veterinary hematology. Philadelphia: Lea \& Fabinger, 1993. 417 p.

LEFCOURT, A. M.; ELSASSER, T. H. Adrenal responses to Angus X Hereford cattle to the stress of weaning. $J$. Anim. Sci., Madison, v. 73, n. 9, p. 2669-2676, 1995.

LOERCH, S. C.; FLUHARTY, F. L. Physiological changes and digestive capabilities of newly received feedlot cattle. J. Anim. Sci., Madison, v. 77, n. 5, p. 11131119, 1999.

PAES, P. R. O.; ROSA, E. P.; BARIONI, G.; FONSECA, L. A.; ARRIGONI, M. B.; MARTINS, C. L.; TAKAHIRA, R. K.; GONÇALVES, R. C. Leucograma de bovinos Nelore, Simental, Simbrasil e mestiços 
Nelore X Simental de mesma idade (10 a 12 meses) em regime de confinamento. In: CONGRESSO LATINO AMERICANO DE BUIATRIA, 11; CONGRESSO BRASILEIRO DE BUIATRIA, 5; CONGRESSO NORDESTINO DE BUIATRIA, 3., 2003, Salvador, BA. Anais... Salvador: Associação Brasileira de Buiatria, 2003. p. 40.

PHILLIPS, W. A.; JUNIEWICZ, P. E.; ZAVY, M. T.; VON TUNGELN, D. L.; VON TUNGELN, D. L. The effect of the stress of weaning and transport on white blood cell patterns and fibrinogen concentration of beef calves of different genotypes. Canad. J. Anim. Sci., Otawa, v. 69, n. 2, p. 333-340, 1989.

SMITH, D. L.; WIGGERS, D. L.; WILSON, L. L.; COMERFRD, J. W.; HARPSTER, H. W.; CASHH, E. H. Postweaning behavior and growth performance of early and conventionally weaned beef calves. Prof. Anim. Sci., Champaign, v. 19, n. 1, p. 23-29, 2003.

SMITH, G. S. Neutrophils. In: FELDMAN, B.; ZINKL, J.; JAIN, N. C. Schalm's veterinary hematology. 5. ed. Philadelphia: Lippincott Williams \& Wilkins, 2000. cap. 46, p. 281-296.

STEINHARDT, M. Reactions of young cattle from a suckler herd to shorthaul transport by road. Repeated investigations before and after permanent separation of young cattle. Dtsch. Tierarztl. Wochenschr., Hannover, v. 109, n. 5, p. 239-245, 2002.

STOCKHAM, S. L.; SCOTT, M. A. Fundamentals of veterinary clinical pathology. Iowa: Blackwell Publishing Company, 2002. 610 p.

TADICH, N.; GALLO, C.; ESCHEVERRIA, R.; van SCHAIK, G. Efecto del ayuno durante dos tiempos de confinamiento y de transporte terrestre sobre algunas variables sanguíneas indicadoras de estres en novillos. Arch. Med. Vet., Valdivia, v. 35, n. 2, p. 171-185, 2003.

VILARROEL, M.; MARIA, G.; SANUDO, C.; GARCIABELENGUER, S.; CHACON, G.; GEBRESENBET, G. Effect of commercial transport in Spain on cattle welfare and meat quality. Dtsch. Tierarztl. Wochenschr., Hannover, v. 110, n. 3, p. 105-107, 2003.

WERNICKI, A.; URBAN-CHMIEL, R.; KANKOFER, M.; MIKUCKI, P.; PUCHALSK, A.; TOKARZEWSKI, $\mathrm{S}$. Evaluation of plasma cortisol and TBARS levels in calves after short - term transportation. Revue Méd. Vet., Toulouse, v. 157, n. 1, p. 30-34, 2006.

ZAR, J. G. Bioestatiscal analysis. 2. ed. Englewood Cliffs: Prentice-Hall, 1984. 718 p. 
